Check for updates

Cite this: Chem. Sci., 2019, 10, 4430

๑ All publication charges for this article have been paid for by the Royal Society of Chemistry

Received 14th February 2019

Accepted 12th March 2019

DOI: $10.1039 / \mathrm{c} 9 \mathrm{sc} 00783 \mathrm{k}$

rsc.li/chemical-science

\section{Nickel-catalyzed $\mathrm{C}-\mathrm{N}$ bond activation: activated primary amines as alkylating reagents in reductive cross-couplingt}

\author{
Huifeng Yue, (D) $\ddagger^{a}$ Chen Zhu, (D) $t^{a}$ Li Shen, ${ }^{a}$ Quyang Geng, ${ }^{a}$ Katharina J. Hock, (D) ${ }^{a}$ \\ Tingting Yuan, ${ }^{a}$ Luigi Cavallo (D)*b and Magnus Rueping (D)*ab
}

Nickel-catalyzed reductive cross coupling of activated primary amines with aryl halides under mild reaction conditions has been achieved for the first time. Due to the avoidance of stoichiometric organometallic reagents and external bases, the scope regarding both coupling partners is broad. Thus, a wide range of substrates, natural products and drugs with diverse functional groups are tolerated. Moreover, experimental mechanistic investigations and density functional theory (DFT) calculations in combination with wavefunction analysis have been performed to understand the catalytic cycle in more detail.

\section{Introduction}

Transition-metal-catalyzed cross-coupling reactions play an important role in modern organic synthesis. ${ }^{1}$ Among them, reductive cross-coupling which uses two electrophiles as coupling partners represents an attractive catalytic platform for the formation of diverse chemical bonds. ${ }^{2}$ Due to the avoidance of stoichiometric organometallic reagents this transformation often possesses a broader substrate scope. Traditionally, alkyl halides, ${ }^{3}$ which may have limited stability and availability, have been used as alkyl electrophiles. Recently, $N$-hydroxyphthalimide esters, anhydrides, benzyl oxalates, tosylates and mesylates have been reported as alkyl coupling partners. ${ }^{4}$ However, the use of primary amines as readily available, cheap, green and stable alkylating reagents in reductive cross-coupling has not been described. Recently, bench-stable pyridinium salts have been reported to be attractive substrates in deaminative cross-coupling with boronic acids. ${ }^{5}$ In this transformation, the radical is generated via a single electron transfer (SET) pathway between the pyridinium salt and the nickel catalyst. In addition, an alkyl radical can be formed by a photoinduced SET process ${ }^{6}$ or by an elegant metal-free formation of a boron-based electrondonor-acceptor (EDA) complex ${ }^{7}$ under blue light irradiation. Also, a Lewis base promoted $\mathrm{C}-\mathrm{N}$ borylation has been reported. ${ }^{8}$ As part of our continuing efforts in metal catalyzed functional group interconversion and the activation of inert bonds, ${ }^{9}$ we

${ }^{a}$ Institute of Organic Chemistry, RWTH Aachen University, Landoltweg 1, D-52074 Aachen, Germany. E-mail: magnus.rueping@rwth-aachen.de

${ }^{b}$ KAUST Catalysis Center, KCC, King Abdullah University of Science and Technology, KAUST, Thuwal 23955-6900, Saudi Arabia

† Electronic supplementary information (ESI) available. See DOI: 10.1039/c9sc00783k

\$ These authors contributed equally to this work. herein describe the first Ni-catalyzed deaminative reductive cross-coupling of activated primary amines with aryl halides, providing a versatile method for the transformation of amino groups to aryl motifs under mild conditions (Scheme 1).

\section{Results and discussion}

We started our investigation by evaluating the reductive crosscoupling of cyclohexylamine derived pyridinium salt 1a and iodobenzene 2a using $\mathrm{NiCl}_{2} \cdot \mathrm{dme}$ as the catalyst, bipyridine ligand $\mathbf{L 1}$ as the ligand and a reducing agent (Table 1). Since solvents typically play an important role in cross-coupling reactions, we first tested several solvents (entries 1-5) and found DMA to be the optimal solvent. Subsequently the ratio of reactants 1a and 2a was evaluated (entries 6 and 7) and the yield was improved to $61 \%$. Bidentate as well as tridentate $N$-containing ligands L1-L4 can be applied (entries 8-10) and L1, L2,

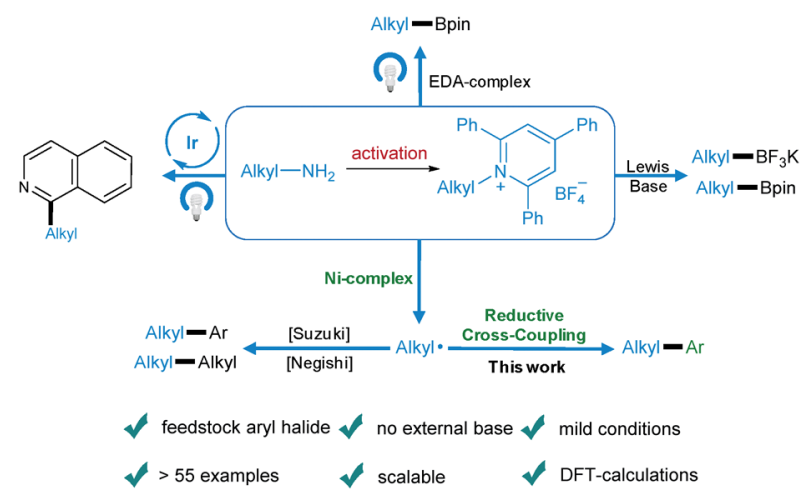

Scheme 1 Diverse activation modes of pyridinium salts and the advantages of this novel deaminative reductive cross-coupling protocol. 
Table 1 Optimization of the reaction conditions ${ }^{a}$

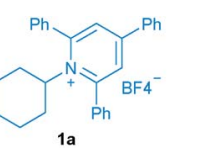

$1 \mathrm{a}$

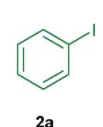

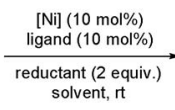
solvent, it

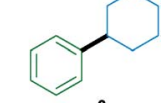

3a

\begin{tabular}{|c|c|c|c|c|c|}
\hline Entry & {$[\mathrm{Ni}]$} & Ligand & Reductant & Solvent & Yield $^{b}(\%)$ \\
\hline 1 & $\mathrm{NiCl}_{2} \cdot \mathrm{dme}$ & L1 & $\mathrm{Zn}$ & DMA & 29 \\
\hline 2 & $\mathrm{NiCl}_{2} \cdot \mathrm{dme}$ & L1 & $\mathrm{Zn}$ & DMF & 11 \\
\hline 3 & $\mathrm{NiCl}_{2} \cdot \mathrm{dme}$ & L1 & $\mathrm{Zn}$ & $\mathrm{CH}_{3} \mathrm{CN}$ & 10 \\
\hline 4 & $\mathrm{NiCl}_{2} \cdot \mathrm{dme}$ & L1 & $\mathrm{Zn}$ & THF & 16 \\
\hline 5 & $\mathrm{NiCl}_{2} \cdot \mathrm{dme}$ & L1 & $\mathrm{Zn}$ & Toluene & 0 \\
\hline $6^{c}$ & $\mathrm{NiCl}_{2} \cdot \mathrm{dme}$ & L1 & $\mathrm{Zn}$ & DMA & 61 \\
\hline $7^{d}$ & $\mathrm{NiCl}_{2} \cdot \mathrm{dme}$ & L1 & $\mathrm{Zn}$ & DMA & 36 \\
\hline $8^{c}$ & $\mathrm{NiCl}_{2} \cdot \mathrm{dme}$ & $\mathbf{L} 2$ & $\mathrm{Zn}$ & DMA & 61 \\
\hline $9^{c}$ & $\mathrm{NiCl}_{2} \cdot \mathrm{dme}$ & L3 & $\mathrm{Zn}$ & DMA & 49 \\
\hline $10^{c}$ & $\mathrm{NiCl}_{2} \cdot \mathrm{dme}$ & L4 & $\mathrm{Zn}$ & DMA & 60 \\
\hline $11^{c}$ & $\mathrm{NiBr}_{2} \cdot \mathrm{dme}$ & $\mathbf{L} 2$ & $\mathrm{Zn}$ & DMA & 51 \\
\hline $12^{c}$ & $\mathrm{Ni}(\mathrm{OAc})_{2} \cdot 4 \mathrm{H}_{2} \mathrm{O}$ & $\mathbf{L} 2$ & $\mathrm{Zn}$ & DMA & 15 \\
\hline $13^{c}$ & $\mathrm{Ni}(\mathrm{acac})_{2}$ & L2 & $\mathrm{Zn}$ & DMA & 35 \\
\hline $14^{c}$ & $\mathrm{NiCl}_{2} \cdot 6 \mathrm{H}_{2} \mathrm{O}$ & $\mathbf{L} 2$ & $\mathrm{Zn}$ & DMA & 35 \\
\hline $15^{c}$ & $\mathrm{NiCl}_{2} \cdot \mathrm{dme}$ & L2 & $\mathrm{Mg}$ & DMA & 8 \\
\hline $16^{c}$ & $\mathrm{NiCl}_{2} \cdot \mathrm{dme}$ & $\mathbf{L} 2$ & $\mathrm{Mn}$ & DMA & 99 \\
\hline $17^{c, e}$ & $\mathrm{NiCl}_{2} \cdot \mathrm{dme}$ & $\mathbf{L} 2$ & $\mathrm{Mn}$ & DMA & 81 \\
\hline $18^{c}$ & - & L2 & $\mathrm{Mn}$ & DMA & 0 \\
\hline $19^{c}$ & $\mathrm{NiCl}_{2} \cdot \mathrm{dme}$ & - & $\mathrm{Mn}$ & DMA & 6 \\
\hline $20^{c}$ & $\mathrm{NiCl}_{2} \cdot \mathrm{dme}$ & L2 & - & DMA & 0 \\
\hline & & $\begin{array}{l}R=t B u \\
R=H \\
R=O M e\end{array}$ & L4: & & \\
\hline
\end{tabular}

${ }^{a}$ Reaction conditions: Katritzky pyridinium salt $1 \mathrm{a}(0.1 \mathrm{mmol})$, iodobenzene $2 \mathrm{a}(0.1 \mathrm{mmol}),[\mathrm{Ni}](0.01 \mathrm{mmol})$, ligand $(0.01 \mathrm{mmol})$, reductant (2 equiv.) in $1.0 \mathrm{ml}$ solvent at rt. ${ }^{b}$ GC yield using decane as the internal standard. ${ }^{c}$ The ratio of $1 \mathrm{a}$ to $2 \mathrm{a}$ was set at $1.5: 1{ }^{d}$ The ratio of 1a to $2 \mathbf{a}$ was set at $1: 2 .{ }^{e}$ Bromobenzene was used instead of iodobenzene.

and L4 showed a similar efficiency, providing the desired product in about $60 \%$ yield. With the readily available and cheap bipyridine $\mathbf{L} 2$, we examined a series of nickel catalysts, including $\mathrm{NiBr}_{2} \cdot \mathrm{dme}, \mathrm{Ni}(\mathrm{OAc})_{2} \cdot 4 \mathrm{H}_{2} \mathrm{O}, \mathrm{Ni}(\mathrm{acac})_{2}$, and $\mathrm{NiCl}_{2^{-}}$ $\cdot 6 \mathrm{H}_{2} \mathrm{O}$. However lower yields were observed (entries 11-14). The yield was significantly improved to $99 \%$ when Mn powder was used as a reductant (entry 16), whereas the utilization of $\mathrm{Mg}$ powder gave the desired product in only $8 \%$ yield (entry 15 ). Besides aryl iodides, the protocol was also applied to aryl bromides. When bromobenzene was used, the desired product was also obtained in a good yield (entry 17). Control experiments demonstrated that the nickel catalyst, ligand, and reductant are all essential for the success of this transformation (entries 18-20).

With the optimized reaction conditions in hand, the scope of aryl halides was first evaluated (Table 2a). A wide variety of aryl halides bearing electron-donating, electron-neutral, and electron-withdrawing functional groups could be successfully converted into the corresponding products in good to excellent yields. For example, phenyl and biphenyl iodides and bromides underwent this reaction smoothly, giving the corresponding products in excellent yields ( $3 \mathbf{a}$ and $\mathbf{3 b}$ ).

In addition, a wide range of functional groups including ketone (3c and 3d), trifluoromethyl (3e), trifluoromethoxy (3f), trifluoromethylthio (3g), tosyl (3h), cyano (3i and $\mathbf{3 m}$ ), methoxy (3j), methylthio (3k), $t$-butyl (31), fluoro ( $3 \mathbf{m}, 3 \mathbf{r}$ and $5 \mathbf{k}$ ), and ester $(\mathbf{5 j})$ were well tolerated under the mild reaction conditions, highlighting the high chemoselectivity of this newly developed deaminative reductive cross-coupling reaction. Use of disubstituted aryl bromide and bicyclic substrates including phthalides and naphthyl halides also gave the products $\mathbf{3 m}-\mathbf{3} \mathbf{p}$ in good yields. It is noteworthy that pharmaceutically relevant 3and 4- bromopyridines could be applied to this protocol with good to high efficiency $(\mathbf{3 q - 3}, \mathbf{s}, \mathbf{5 n})$. Next, the scope of pyridinium salts was explored. A wide range of structurally diverse pyridinium salts were suitable substrates for this transformation. Cyclic and acyclic secondary amine substrates could undergo this deaminative arylation reaction in good to excellent yield $(\mathbf{4 a}-\mathbf{4 g})$ and the same applies for $N$-heterocyclic pyridinium salts (4h and $4 \mathbf{i}$ ) (Table $2 \mathrm{~b}$ ).

It should be mentioned that when we applied primary alkyl pyridinium salts to this protocol, the reaction did not occur. However, simply switching the ligand from $\mathbf{L} 2$ to $\mathbf{L} \mathbf{4}$ and slightly raising the reaction temperature to $60{ }^{\circ} \mathrm{C}$ allowed this transformation to occur smoothly. A series of primary alkyl pyridinium salts bearing diverse functional groups such as amine, acetal, dioxole, cyclohexenyl, thiophene, and pyridine were suitable coupling partners for this deaminative reductive crosscoupling, leading to products $\mathbf{4 n - 4 s}$. Notably, chloro (4k), unprotected $\mathrm{OH}$ and indole $\mathrm{NH}$ groups were also tolerated (4t and 5f), providing the option for further functionalization. Moreover, methylation reaction, which is challenging in reductive cross-coupling, was also realized via the utilization of methyl pyridinium salts (Table 2c). Importantly, our newly developed protocol could also be readily extended to a wide range of complex molecules derived from natural products and drugs. As such pregnenolone, galactopyranose, probenecid, adamantane carboxylic acid, and cholestanol derivatives could be transformed to the corresponding products $\mathbf{5 a}-\mathbf{5 e}$ in good to excellent yield. Moreover, a series of pyridinium salts derived from drugs or drug intermediates, including tryptamine, mexiletine, amphetamine, Lipitor intermediate, and dopamine, all underwent the mild coupling protocol with good to excellent efficiency $(\mathbf{5 f}-\mathbf{5 n})$. Use of Mosapride derived pyridinium salts gave product $\mathbf{5 o}$ in a lower yield (Table $2 \mathrm{~d}$ ).

Additionally, a gram-scale reaction was successfully conducted using $\mathbf{1 a}$ and 4-iodobiphenyl $\mathbf{2 b}$ in the presence of only $5 \mathrm{~mol} \%$ nickel catalyst and the desired product $3 \mathbf{b}$ was obtained in $96 \%$ yield (Scheme 2a), demonstrating the practicability of our newly developed deaminative reductive cross-coupling methodology. Also, byproduct $\mathbf{6}$, which is potentially a useful organic base, could be isolated in $85 \%$ yield. To shed light on the mechanism of this transformation, an experiment was conducted with the radical trapping reagent TEMPO $(2,2,6,6-$ tetramethyl-1-piperidinyloxy, 2 equiv.). ${ }^{5 a, c}$ The reaction was suppressed and no product $\mathbf{5 m}$ was detected (Scheme $2 \mathrm{~b}$ ). 


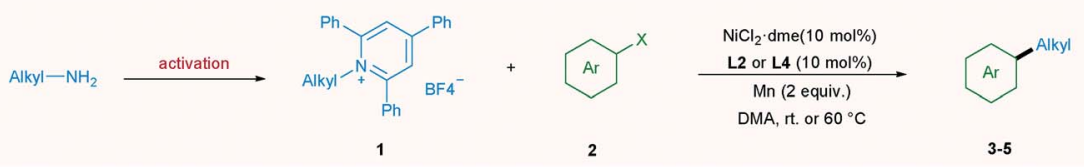
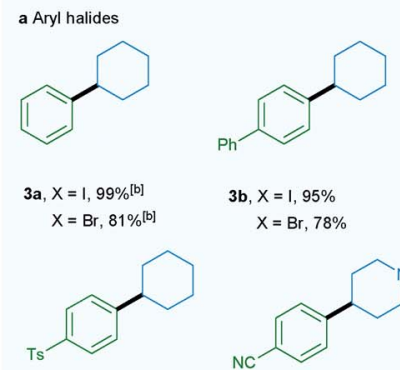

3b, $X=1,95 \%$<smiles></smiles>

$3 h, X=1,32 \%$<smiles>c1ccc2cc(C3CCCCC3)ccc2c1</smiles>

3o, $\mathrm{X}=\mathrm{Br}, 61 \%$

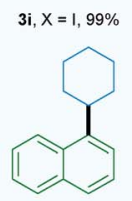

3p, $x=1,71 \%$

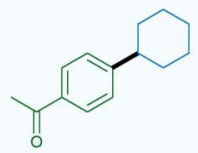

3c, $X=1,92 \%$<smiles>O=C(c1ccccc1)c1ccc(C2CCCCC2)cc1</smiles><smiles>FC(F)(F)c1ccc(C2CCCCC2)cc1</smiles><smiles>O=[N+]([O-])c1ccc(C2CCCCC2)cc1</smiles>

3e, $X=1,66 \%$<smiles>COc1ccc(C2CCCCC2)cc1</smiles><smiles>Cc1ccc(C2CCCCC2)cc1</smiles><smiles>N#Cc1ccc(C2CCCCC2)cn1</smiles>

3q, $X=B r, 64 \%$<smiles>Cc1cc(C2CCCCC2)ccn1</smiles>

$3 \mathbf{r}, \mathrm{X}=\mathrm{Br}, 67 \%$

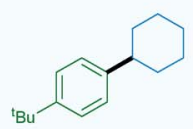

31 $\mathrm{X}=\mathrm{I}, 51 \%$<smiles>N#Cc1cc(C2CCCCC2)ccn1</smiles>

3s, $\mathrm{X}=\mathrm{Br}, 72 \%$

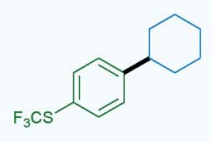

3g, $\mathrm{X}=\mathrm{Br}, 77 \%$<smiles>N#Cc1ccc(C2CCN(C(=O)c3ccccc3)CC2)cc1F</smiles>

$3 \mathrm{~m}, \mathrm{X}=\mathrm{Br}, 99 \%$

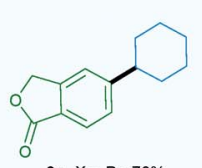

3n, $X=B r, 79 \%$

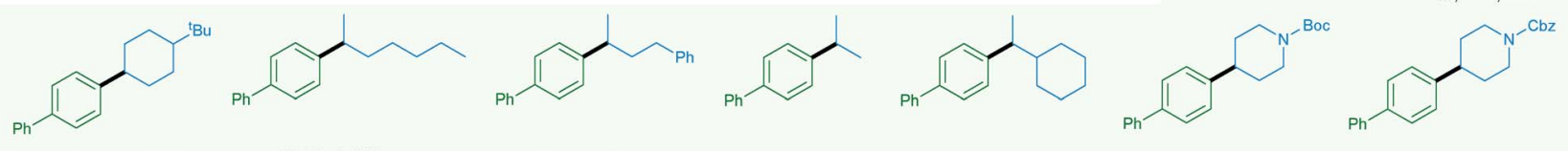

$4 c, X=I, 88 \%$, d.r. $62: 38$

4d, $X=1,82 \%$

$4 e, X=1,79 \%$

4f, $X=1,88 \%$

4g, $X=1,72 \%$

4h, $X=1,94 \%$

4i, $X=1,96 \%$

c Primary alkyl

4j, $X=I, 74 \%$<smiles>CC1(C)COC(Cc2ccc(-c3ccccc3)cc2)O1</smiles>

4p, $X=1,56 \%$<smiles>Clc1ccc(CCc2ccc(Br)cc2)cc1</smiles>

4k, $X=1,65 \%$

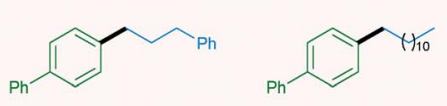

4l, $X=1,78 \%$

4m, $X=1,92 \%$<smiles>c1ccc(CCc2cccs2)cc1</smiles>

4r. $X=1,40 \%$<smiles>c1ccc(CCc2ccccn2)cc1</smiles>

$4 s, X=1,17 \%$

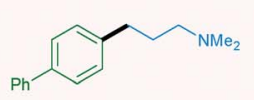

4n, $X=I, 72 \%$<smiles>OCCCCCc1ccc(-c2ccccc2)cc1</smiles>

4t, $X=1,74 \%$

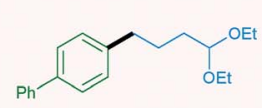

4o, $X=1,53 \%$

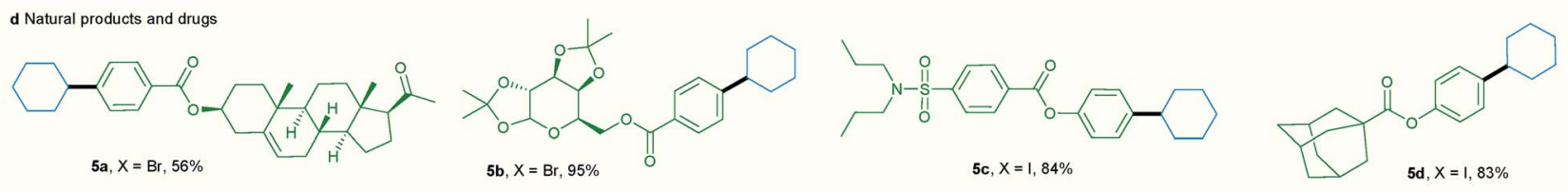

5a, $\mathrm{X}=\mathrm{Br}, 56 \%$

5b, $\mathrm{X}=\mathrm{Br}, 95 \%$

5c, $X=1,84 \%$

5d, $X=1,83 \%$

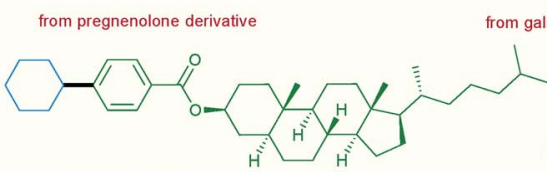

5e, $X=1,87 \%$ H

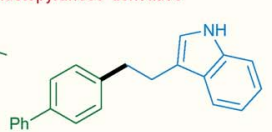

5f, $X=1,61 \%$

om tryptamine derivative

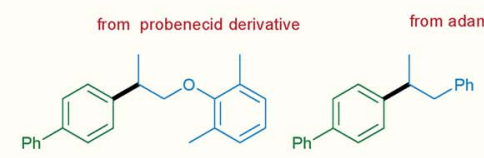

5g, $X=1,84 \%$ from Mexiletine derivative
$5 h, X=1,74 \%$

from amphetamine derivative
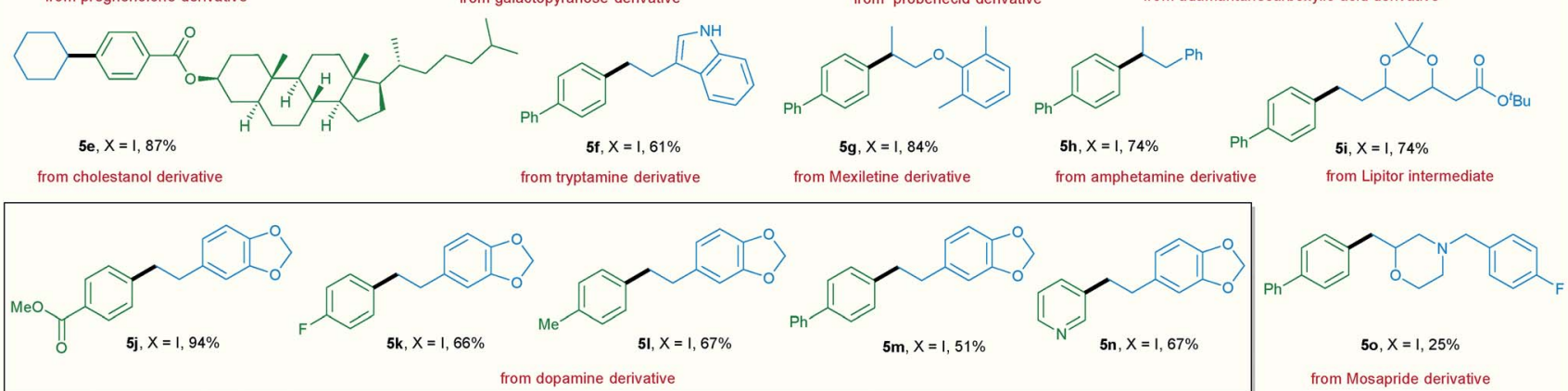

\footnotetext{
${ }^{a}$ Reaction conditions: pyridinium salt $\mathbf{1}(0.30 \mathrm{mmol})$, aryl halide $2(0.20 \mathrm{mmol}), \mathrm{NiCl}_{2} \cdot \mathrm{dme}(0.02 \mathrm{mmol}), \mathbf{L} 2(0.02 \mathrm{mmol}$, for secondary alkyl) or $\mathbf{L} \mathbf{4}$ $\left(0.02 \mathrm{mmol}\right.$, for primary alkyl), Mn powder $(0.40 \mathrm{mmol})$ in $1.0 \mathrm{ml}$ DMA at $\mathrm{rt}$ (for secondary alkyl) or $60^{\circ} \mathrm{C}$ (for primary alkyl); yields after purification. ${ }^{b}$ GC yield. ${ }^{c}$ The ratio of pyridinium salt to aryl halide $1: 3,100{ }^{\circ} \mathrm{C}$, NMR yield.
} 

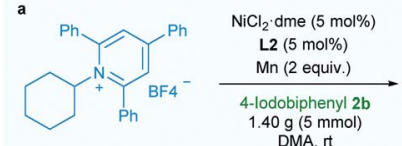

1a, $7.5 \mathrm{mmol}, 3.58 \mathrm{~g}$

b

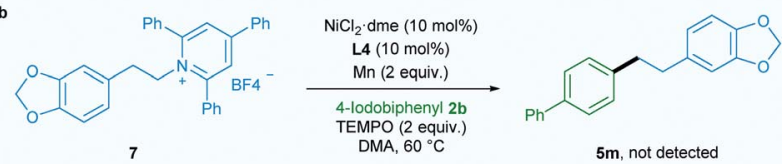

c

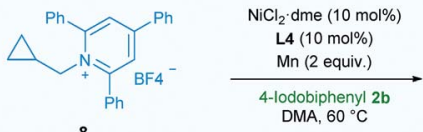

d
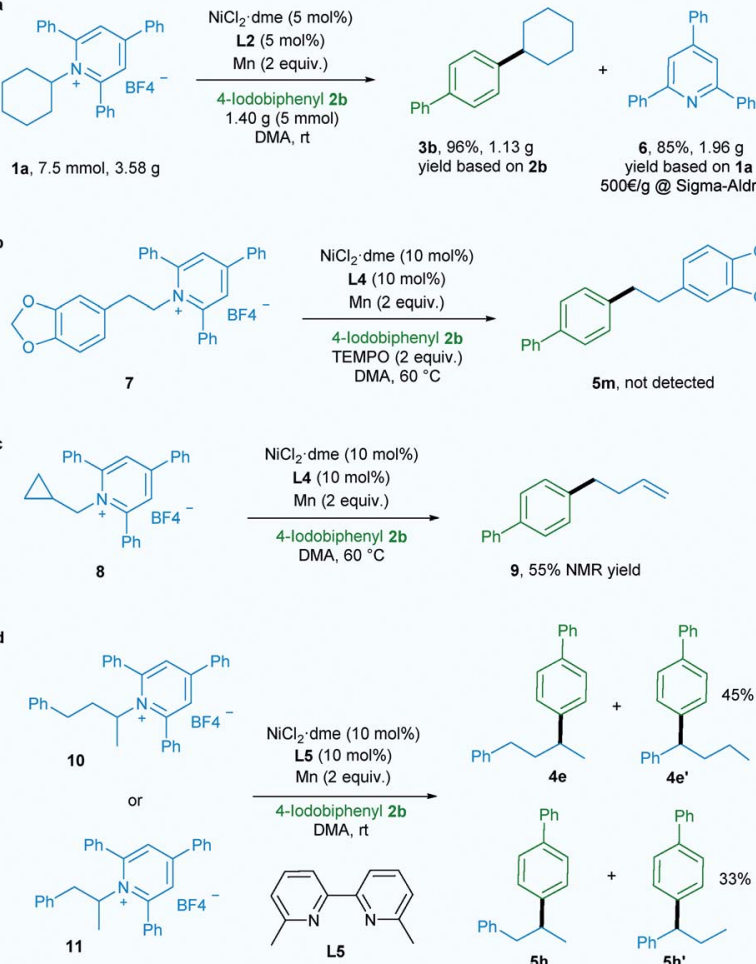

$6,85 \%, 1.96 \mathrm{~g}$ yield based on $1 \mathrm{a}$ 500€/g @ Sigma-Aldrich

Scheme 2 Gram-scale reaction and mechanism investigation.
Also, ring-opened product 9 was generated in 55\% yield when a substrate bearing a cyclopropane motif $\mathbf{8}$ was used (Scheme 2c). ${ }^{5 a, c}$ Both these results suggest the involvement of an alkyl radical in this transformation. When ligand $\mathbf{L 5}$ which is effective for chain-walking reductive cross-coupling ${ }^{10}$ was used in our catalytic system, non-walking and chain-walking products $\left(4 \mathbf{e}\right.$ and $4 \mathbf{e}^{\prime}, 5 \mathbf{h}$ and $\left.5 \mathbf{h}^{\prime}\right)$ were obtained with a ratio of $4: 1$, suggesting an oxidative addition of aryl halide to $\mathrm{Ni}^{0}$ to give a $\mathrm{Ni}^{\mathrm{II}}$ intermediate prior to alkyl radical generation. Since the $\mathrm{Ni}^{\mathrm{III}}$ intermediate generated from addition of the alkyl radical to the $\mathrm{Ni}^{\mathrm{II}}$ intermediate is less likely to undergo the chain-walking step due to steric hindrance the non-chain-walking product is the major product.

Furthermore, detailed DFT calculations were performed to rationalize our newly designed catalytic reaction (Scheme 3; computational methods, see ESI $\dagger$ ). As a model system, we investigated the reaction of phenyl bromide with $\mathbf{A 1}$ in the presence of $\mathrm{NiCl}_{2} \cdot \mathrm{dme}$, bpy as the ligand and $\mathrm{Mn}$ as the reducing agent. The reaction starts with the complexation of the ligand bpy to the $\mathrm{Ni}^{\mathrm{II}}$ precatalyst, followed by reduction to form the active $\mathrm{Ni}^{0}$ catalyst $\mathbf{B}$ (Scheme $\mathrm{S} 1$ in $\mathrm{ESI} \uparrow$ ). The catalytic process is initiated by oxidative addition of phenyl bromide to $\mathrm{Ni}^{0}$ via transition state B-TS with an energy barrier of $11.7 \mathrm{kcal} \mathrm{mol}^{-1}$. The formed $\mathrm{Ni}^{\mathrm{II}}$ intermediate $\mathbf{C}$ is reduced by $\mathbf{M n}$, leading to intermediate $\mathbf{D}$ with a free energy gain of $6.9 \mathrm{kcal} \mathrm{mol}^{-\mathbf{1}}$. In the next step, $\mathbf{A 1}$ is coordinated to $\mathbf{D}$, followed by SET reduction of $\mathbf{A 1}$ to generate radical $\mathbf{A 2}$ and $\mathrm{Ni}^{\mathrm{II}}$ intermediate $\mathbf{F}$. The radical $\mathbf{A} 2$ is prone to undergo $\mathrm{C}-\mathrm{N}$ bond cleavage with an energy barrier of $19.9 \mathrm{kcal} \mathrm{mol}^{-1}$, liberating the alkyl radical $\mathbf{A} 3$ and the aromatic pyridine $\mathbf{A 4}$. At this point, alkyl

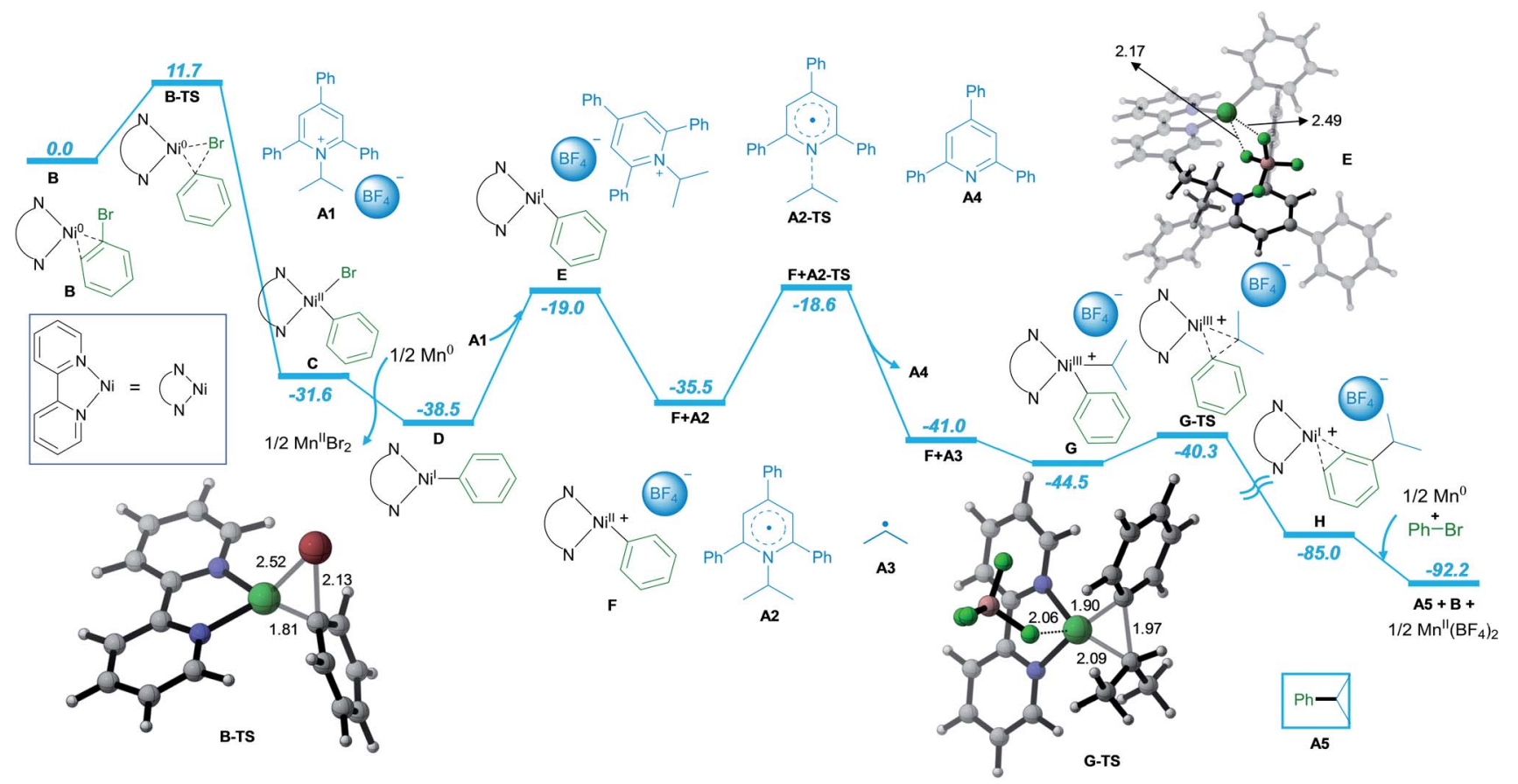

Scheme 3 DFT-Computed energy profile for the nickel-catalyzed reductive cross-coupling reaction of aryl halides and pyridinium salts. Free

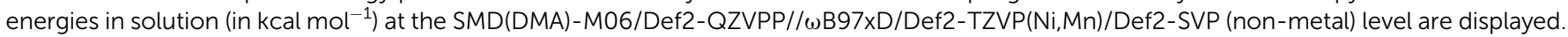
Selected DFT optimized geometries are listed. Bond lengths are in $\AA$. 
radical $\mathbf{A} 3$ adds to $\mathrm{Ni}^{\mathrm{II}}$ intermediate $\mathbf{F}$ to form $\mathrm{Ni}^{\mathrm{III}}$ intermediate G. Subsequently, the $\mathrm{C}-\mathrm{C}$ bond cross-coupling product $\mathbf{A 5}$ is formed via reductive elimination from $\mathrm{Ni}^{\mathrm{III}}$ with an energy barrier of $4.9 \mathrm{kcal} \mathrm{mol}^{-1}$.

Finally, the $\mathrm{Ni}^{\mathrm{I}}$ intermediate $\mathbf{H}$ is further reduced by $\mathrm{Mn}$ to regenerate the $\mathrm{Ni}^{0}$ active catalyst $\mathbf{B}$ and initiate the next catalytic cycle.

Subsequently, we focused on the origin of the SET reduction of the pyridinium salt and the generation of the alkyl radical. ${ }^{11}$ The molecular orbital plots (Fig. 1a) show that the SOMO of $\mathbf{E}$ corresponds to the singly occupied MO predominantly localized

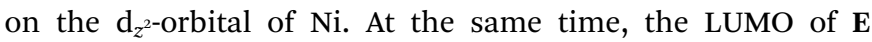
corresponds to a $\pi$-orbital delocalized around the central nitrogen-containing aromatic ring of the pyridinium salt. However, after A2 is displaced away from the Ni species, the SOMO becomes localized on the central aromatic ring of the pyridinium salt. This indicates that upon separation of the $\mathrm{Ni}$ and pyridyl fragments the unpaired electron transfers from $\mathrm{Ni}$ to the pyridinium salt and delocalizes around the central aromatic ring. Spin density analysis further supported this process. The unpaired electron density is localized on the Nicenter when the pyridinium salt is coordinated to the $\mathrm{Ni}^{\mathrm{I}}$ complex, as in $\mathbf{E}$ (Fig. 1b, left), while it is transferred to the central pyridine ring as the pyridine moiety $\mathbf{A} 2$ dissociates from the Ni complex (Fig. 1b, middle). Subsequently, the $\mathrm{C}-\mathrm{N}$ bond dissociates and the spin density is further transferred to the $\mathrm{sp}^{3}$ carbon atom, indicating generation of the alkyl radical (Fig. 1b, right). Additionally, cyclic voltammetry (CV) measurements of

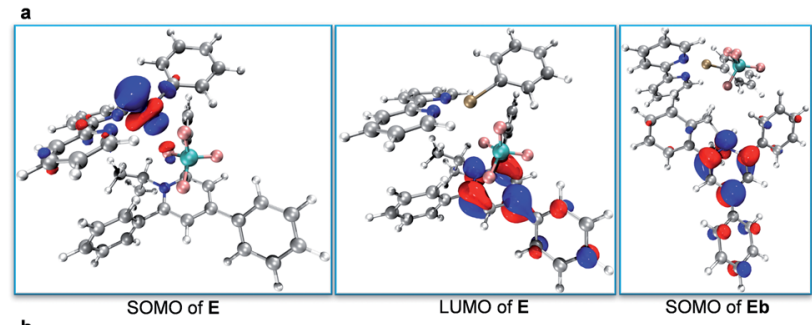

b
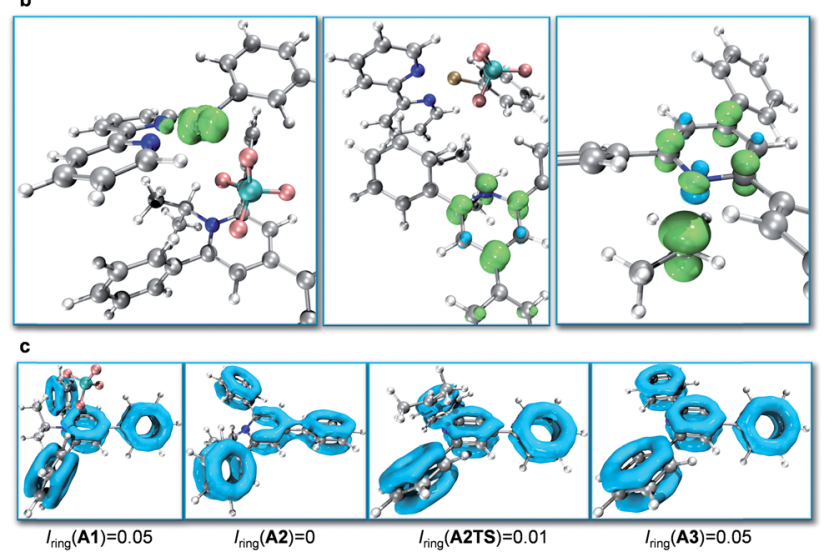

Fig. 1 (a) Molecular orbital plots: SOMO of E (left), LUMO of E (middle) and SOMO of Eb (right). (b) Spin density plots of $\mathrm{E}$ (left), Eb (middle) and A2TS (right). (c) Localized orbital locator (LOL) - $\pi$ plots of A1, A2, $\mathrm{A} 2 \mathrm{TS}$, and $\mathrm{A} 3$ with multi-center bond order of the central nitrogencontaining aromatic ring $I_{\text {ring }}$ listed below. the pyridinium salt were conducted (see ESI $\dagger$ ) and reversible peaks at $-0.94 \mathrm{~V} v s$. SCE were observed, suggesting the existence of stable radical intermediate $\mathbf{A 2}$. In order to understand the $\mathrm{C}-\mathrm{N}$ bond dissociation, we performed localized orbital locator (LOL) $-\pi$ analysis $^{\mathbf{1 2}}$ and multi-center bond order calculations $\left(I_{\text {ring }}\right)^{\mathbf{1 3}}$ for the whole process (Fig. 1c). Before the SET reduction, the central pyridine ring has full aromaticity ( $I_{\text {ring }}=0.05$ in A1, for comparison, $I_{\text {ring }}=0.05$ in benzene and pyridine $\left.{ }^{12 c}\right)$. After the reduction the aromaticity is lost and the free energy is $3.0 \mathrm{kcal} \mathrm{mol}^{-1}$ higher $\left(I_{\text {ring }}=0 \mathrm{in} \mathrm{A2}\right)$. With the $\mathrm{C}-\mathrm{N}$ bond dissociating, the aromaticity is partially regained (c.f. $I_{\text {ring }}=0.01$ in transition state A2TS). After the generation of alkyl radicals, the aromaticity of $\mathbf{A} 3$ is fully restored $\left(I_{\text {ring }}=0.05\right.$ in A3) with a free energy gain of $5.5 \mathrm{kcal} \mathrm{mol}^{-1}$.

\section{Conclusions}

In summary, we have developed a new deaminative reductive cross-coupling of aryl halides with pyridinium salts derived from readily available alkyl amines. Due to the avoidance of stoichiometric organometallic reagents and external bases, the scope is rather broad as demonstrated using the many different substrates employed ( $>55$ examples). In addition, the chemoselectivity of this protocol is good and functional groups, including cyano, methoxy, methylthio, fluoro as well as chloro, unprotected $\mathrm{OH}$ and indole $\mathrm{NH}$ groups, are well tolerated. Importantly, the cross-coupling reaction can be scaled-up using a lower amount of nickel catalyst without diminishing the yield, demonstrating the practicability of this protocol. Furthermore, experimental mechanistic investigations and DFT calculations combined with wavefunction analysis have been conducted to gain insight into the catalytic process.

\section{Conflicts of interest}

There are no conflicts to declare.

\section{Acknowledgements}

H. Y. acknowledges the China Scholarship Council. C. Z. acknowledges the King Abdullah University of Science and Technology (KAUST) for support and the KAUST Supercomputing Laboratory for providing computational resources of the supercomputer Shaheen II.

\section{Notes and references}

1 (a) T. J. Colacot, New Trends in Cross-Coupling: Theory and Applications, RSC Publishing, Cambridge, 2014; (b) A. d. Meijere, S. Bräse and M. Oestreich, Metal-Catalyzed Cross-Coupling Reactions and More, Wiley-VCH, Weinheim, 2014.

2 (a) C. E. Knappke, S. Grupe, D. Gärtner, M. Corpet, C. Gosmini and A. Jacobi von Wangelin, Chem.-Eur. J., 2014, 20, 6828-6842; (b) J. Gu, X. Wang, W. Xue and H. Gong, Org. Chem. Front., 2015, 2, 1411-1421; (c) D. J. Weix, Acc. Chem. Res., 2015, 48, 1767-1775. 
3 D. A. Everson, R. Shrestha and D. J. Weix, J. Am. Chem. Soc., 2010, 132, 920-921.

4 Examples of reductive cross couplings with $\mathrm{N}$ hydroxyphthalimide esters: (a) K. M. Huihui, J. A. Caputo, Z. Melchor, A. M. Olivares, A. M. Spiewak, K. A. Johnson, T. A. DiBenedetto, S. Kim, L. K. G. Ackerman and D. J. Weix, J. Am. Chem. Soc., 2016, 138, 5016-5019; (b) L. Huang, A. M. Olivares and D. J. Weix, Angew. Chem., Int. Ed., 2017, 56, 11901-11905; (c) N. Suzuki, J. L. Hofstra, K. E. Poremba and S. E. Reisman, Org. Lett., 2017, 19, 2150-2153; (d) H. Li, C. P. Breen, H. Seo, T. F. Jamison, Y.-Q. Fang and M. M. Bio, Org. Lett., 2018, 20, 1338-1341; (e) X. Lu, X.-X. Wang, T.-J. Gong, J.-J. Pi, S.-J. He and Y. Fu, Chem. Sci., 2019, 10, 809-814; anhydrides: $(f)$ H. Chen, L. Hu, W. Ji, L. Yao and X. Liao, ACS Catal., 2018, 8, 10479-10485; benzyl oxalates: $(g)$ X.-B. Yan, C.-L. Li, W.-J. Jin, P. Guo and X.-Z. Shu, Chem. Sci., 2018, 9, 45294534; tosylates and mesylates: $(h)$ J. H. Liu, C. T. Yang, X. Y. Lu, Z. Q. Zhang, L. Xu, M. Cui, X. Lu, B. Xiao, Y. Fu and L. Liu, Chem.-Eur. J., 2014, 20, 15334-15338.

5 For leading work, see: (a) C. H. Basch, J. Liao, J. Xu, J. J. Piane and M. P. Watson, J. Am. Chem. Soc., 2017, 139, 5313-5316; (b) J. Liao, W. Guan, B. P. Boscoe, J. W. Tucker, J. W. Tomlin, M. R. Garnsey and M. P. Watson, Org. Lett., 2018, 20, 3030-3033; (c) S. Plunkett, C. H. Basch, S. O. Santana and M. P. Watson, J. Am. Chem. Soc., 2019, 141, 2257-2262.

6 (a) F. J. Klauck, M. J. James and F. Glorius, Angew. Chem., Int. Ed., 2017, 56, 12336-12339; (b) X. Jiang, M.-M. Zhang, W. Xiong, L.-Q. Lu and W.-J. Xiao, Angew. Chem., Int. Ed., 2019, 58, 2402-2406; (c) F. J. Klauck, H. Yoon, M. J. James, M. Lautens and F. Glorius, ACS Catal., 2018, 9, 236-241; (d) M. Ociepa, J. Turkowska and D. Gryko, ACS Catal., 2018, 8, 11362-11367.

7 (a) J. Wu, L. He, A. Noble and V. K. Aggarwal, J. Am. Chem. Soc., 2018, 140, 10700-10704; (b) F. Sandfort, F. Strieth-
Kalthoff, F. J. Klauck, M. J. James and F. Glorius, Chem.Eur. J., 2018, 24, 17210-17214.

8 J. Hu, G. Wang, S. Li and Z. Shi, Angew. Chem., Int. Ed., 2018, 57, 15227-15231.

9 Examples: (a) M. Leiendecker, C. C. Hsiao, L. Guo, N. Alandini and M. Rueping, Angew. Chem., Int. Ed., 2014, 53, 12912-12915; (b) L. Guo, A. Chatupheeraphat and M. Rueping, Angew. Chem., Int. Ed., 2016, 55, 11810-11813; (c) L. Guo, C.-C. Hsiao, H. Yue, X. Liu and M. Rueping, ACS Catal., 2016, 6, 4438-4442; (d) L. Guo, X. Liu, C. Baumann and M. Rueping, Angew. Chem., Int. Ed., 2016, 55, 1541515419; (e) X. Liu, C. C. Hsiao, I. Kalvet, M. Leiendecker, L. Guo, F. Schoenebeck and M. Rueping, Angew. Chem., Int. Ed., 2016, 55, 6093-6098; (f) H. Yue, L. Guo, S. C. Lee, X. Liu and M. Rueping, Angew. Chem., Int. Ed., 2017, 56, 3972-3976; (g) H. Yue, L. Guo, H. H. Liao, Y. Cai, C. Zhu and M. Rueping, Angew. Chem., Int. Ed., 2017, 56, 42824285; (h) H. Yue, C. Zhu and M. Rueping, Angew. Chem., Int. Ed., 2018, 57, 1371-1375.

10 F. Chen, K. Chen, Y. Zhang, Y. He, Y.-M. Wang and S. Zhu, J. Am. Chem. Soc., 2017, 139, 13929-13935.

11 (a) Molecular orbital plot, spin density plot, and LOL- $\pi$ plot were visualized by VMD, see: W. Humphrey, A. Dalke and K. Schulten, J. Mol. Graphics, 1996, 14, 33-38; (b) Molecular orbitals, spin density, LOL $-\pi$, and multi-center bond order were analyzed by Multiwfn 3.6. see: T. Lu and F. Chen, J. Comput. Chem., 2012, 33, 580-592.

12 (a) H. Schmider and A. Becke, J. Mol. Struct.: THEOCHEM, 2000, 527, 51-61; (b) V. Tsirelson and A. Stash, Acta Crystallogr., Sect. B: Struct. Sci., 2002, 58, 780-785; (c) H. Jacobsen, Can. J. Chem., 2008, 86, 695-702.

13 (a) M. Giambiagi, M. S. de Giambiagi and K. C. Mundim, Struct. Chem., 1990, 1, 423-427; (b) P. Bultinck, R. Ponec and S. Van Damme, J. Phys. Org. Chem., 2005, 18, 706-718; (c) E. Matito, Phys. Chem. Chem. Phys., 2016, 18, 1183911846. 